\title{
Characterization of Functional Domains in NME1L Regulation of NF-kB Signaling
}

\author{
Dong-Joo You', Cho Rong Park', Sunam Mander', Curie Ahn², Jae Young Seong', and Jong-lk Hwang ${ }^{1, *}$
}

\begin{abstract}
NME1 is a well-known metastasis suppressor which has been reported to be downregulated in some highly aggressive cancer cells. Although most studies have focused on NME1, the NME1 gene also encodes the protein (NME1L) containing N-terminal 25 extra amino acids by alternative splicing. According to previous studies, NME1L has potent anti-metastatic activity, in comparison with NME1, by interacting with IKK $\beta$ and regulating its activity. In the present study, we tried to define the role of the $\mathrm{N}$ terminal 25 amino acids of NME1L in NF-KB activation signaling. Unfortunately, the sequence itself did not interact with IKK $\beta$, suggesting that it may be not enough to constitute the functional structure. Further construction of NME1L fragments and biochemical analysis revealed that $\mathrm{N}$-terminal 84 residues constitute minimal structure for homodimerization, IKK $\beta$ interaction and regulation of NF$\kappa B$ signaling. The inhibitory effect of the fragment on cancer cell migration and NF-KB-stimulated gene expression was equivalent to that of whole NME1L. The data suggest that the $\mathbf{N}$-terminal 84 residues may be a core region for the anti-metastatic activity of NME1L. Based on this result, further structural analysis of the binding between NME1L and IKK $\beta$ may help in understanding the anti-metastatic activity of NME1L and provide direction to NME1L and IKK $\beta$-related anti-cancer drug design.
\end{abstract}

\section{INTRODUCTION}

The NM23 protein family, which is designated as a nonmetastatic gene (NME or NM23), consists of eight members that encode widely expressed proteins known as NME1-8 or NM23H1-8 (Lacombe et al., 2000). Expression of these proteins has been reported to be altered in many cellular processes, such as proliferation, differentiation, motility, development, and apoptosis, implying that they may play essential roles in various intracellular signaling events (Amendola et al., 1997; Dearolf et al.,

\footnotetext{
${ }^{1}$ Graduate School of Medicine, Korea University, Seoul 136-705, Korea, ${ }^{2}$ Transplantation Research Institute, Cancer Research Institute, Seoul National University, Seoul 110-799, Korea

*Correspondence: hjibio@korea.ac.kr
}

Received 25 November, 2015; revised 24 February, 2016; accepted 29 February, 2016; published online 4 April, 2016

Keywords: anti-metastasis, dimerization, IKK $\beta, N F-\kappa B, N M E 1 L$
1988; Keim et al., 1993; Okabe-Kado et al., 1995; Venturelli et al., 1995). All members are characterized as nucleotide diphosphate kinase (NDPK) that are required for the synthesis of nucleoside triphosphates and maintain intracellular nucleotide concentration (Lascu and Gonin, 2000). However, kinase activity itself is not sufficient to explain their biological roles, since some (e.g., NME5, 7, and 8) of them don't catalyze the kinase activity (Lacombe et al., 2000). Furthermore, there is some evidence that each protein might have a unique and diverse function in physiological processes regardless of its kinase activity, although they are ubiquitously expressed and most of them are small proteins ranging from $17 \mathrm{kDa}$ to $20 \mathrm{kDa}$ and highly homologous in peptide composition (Kim et al., 2009; Salerno et al., 2005). NME4 has been reported as an intermembrane lipid transfer as well as phospho-transfer serving local GTP supply in mitochondria (Schlattner et al., 2013). NME5 may play a role in spermiogenesis and sperm motility by localization in the flagella of spermatids and spermatozoa (Munier et al., 2003). NME6 and NME7 are expressed in embryonic stem cells and important for the regulation of stem cell marker protein expression, thereby implying that they are pivotal in embryonic stem cell renewal (Wang et al., 2012). Especially in cancer development, the study with a kinase-deficient mutant revealed that NDPK activity may be dispensable for the anti-metastatic function (Boissan et al., 2010; Tokunaga et al., 1993). Thus, the biological functions of each protein may be ascribed to a distinct structural conformation, interaction with other cellular proteins, and the residual region consisting of different amino acid sequences, although they share common domains responsible for oligomerization.

NME1, also called as NM23, was the first metastatic suppressor gene discovered, and has been studied extensively in cancer progression (Steeg et al., 1988). NME1 proteins are ubiquitously expressed in various tissues and may exist in cytosol as homo- or hetero-hexamers with other NME proteins (Hartsough and Steeg, 2000). Although the protein is small and specific functional domain is not identified, the hexameric conformation may confer NME1 a multifunctional enzymatic activity beyond NDPK, which also acts as histidine/aspartic acidspecific protein kinase and 3'-5' exonuclease (Ma et al., 2002; Postel, 1999; Wallet et al., 1990). Because in vitro studies with mutants lacking the enzymatic activities demonstrated deprivation of anti-metastatic functions, the integrity of its kinase activities may be associated with motility suppression activity and repair of ultraviolet radiation-induced DNA damage and mutagenesis (Yang et al., 2009; Zhang et al., 2011). However, the functional relevance of the enzymatic activity on metastasis 
suppression is still unclear since mutations targeting kinase activity may influence other enzymatic activities or molecular interactions with binding partners (Steeg et al., 2008). According to some reports, enzyme activities might not be essential for the anti-metastatic function in all cancers. For example, NME2, a highly homologous protein to NME1, has equivalent enzymatic activities but its expression pattern is not associated with cancer cell migration and invasion (Boissan et al., 2010; Tokunaga et al., 1993).

NME1 is likely to be involved in many cellular responses by interacting with and regulating various intracellular proteins. In regard to cell motility and migration, NME1 negatively regulates Rac1 and Cdc42 by interacting with their specific guanine nucleotide exchange factors Tiam1 and Dbl-1, respectively (Murakami et al., 2008; Otsuki et al., 2001). Direct interaction with the Rad protein enables NME1 to regulate Rad GDP/GTP cycling by recruiting either a GTPase-activating protein or a guanine nucleotide exchange factor, which may negatively regulate downstream molecules responsible for cytoskeletal organization and cell motility (Tseng et al., 2001; Zhu et al., 1999). Transforming growth factor- $\beta$ (TGF- $\beta$ ) signaling, which is a dominant pathway to trigger invasion and metastasis of advanced cancer cells, may be regulated by NME1 interaction with serine/threonine kinase receptor-associated protein (STRAP) through an intermolecular disulfide bond (Seong et al., 2007). Although underlying mechanisms are not completely understood, NME1 may inhibit cell motility by regulating expression of some proteins, such as a lysophosphatidic acid receptor EDG2 and a matrix metalloproteinase MMP2, which are involved in invasion and metastasis (Cheng et al., 2002; Horak et al., 2007; Kwon et al., 2013). Down-regulated NME1 in many cancer cells is reversely correlated with the increased expression of metastasis-related genes (Martinez et al., 1995; Ouatas et al., 2003).

As aforementioned, NME1 is quite similar to NME2 (93\% identity in amino acids), implying that their biological functions are quite similar to each other. However, NME2 seems not to have anti-metastatic activity, although its roles are still under investigation and thereby subject to debate. Concerning this point, it is an important issue as to how NME1 has distinct functions in cellular responses from NME2. Ten different amino acids from NME2 may induce NME1 to perform unique biological functions, which should be solved by biochemical studies. Interestingly, contrary to NME2, the NME1 gene encodes two proteins (NME1;152aa and NME1L;177aa) by alternative splicing. NME1L has 25 additional $\mathrm{N}$-terminal amino acids from an extra exon. Most functional studies described above have been done on the short form because of its abundance in the cell. Although NME1L is relatively rare, it is necessary to define its biological functions because the $\mathrm{N}$-terminal amino acids may endow the protein with unique roles in cellular responses. Previous studies demonstrated that NME1L specifically interacts with and inhibits IKK $\beta$, which is a dominant activator of NF-KB signaling and involved in cancer progression, through the $\mathrm{N}$-terminal region (You et al., 2014). The interaction leads to downregulation of the NF-kB-dependent expression of cell motility-related genes and the inhibition of lung metastasis of cancer cells, thereby suggesting that NME1L may function as a potent metastasis suppressor compared with NME1. However, the precise biochemical mechanism by which the $\mathrm{N}$-terminal sequence influences NF- $\mathrm{KB}$ signaling has not been characterized.

In the present study, we endeavored to define the role of $\mathrm{N}$ terminal residues of NME1L in NF- $\mathrm{KB}$ activation signaling. Unfortunately, the $\mathrm{N}$-terminal itself did not interact with IKK $\beta$, suggesting that it may not be enough to constitute a functional structure. Further construction of NME1L fragments and biochemical analysis revealed the sequences responsible for IKK $\beta$ interaction and regulation of NF- $\mathrm{KB}$ signaling. This analysis may provide the molecular mechanism to understand roles of NME1L in cancer progression and facilitate to design therapeutic tools regulating enzymatic activity of IKK $\beta$ in cancer.

\section{MATERIALS AND METHODS}

\section{Materials}

All primers and materials for gene construction were obtained from Cosmogenetech (Korea); and the DNA sequencing was conducted by the same company. HEK293 and HT1080 cells were purchased from the American Type Culture Collection (USA). Cell culture media, including Dulbecco's modified eagle medium (DMEM) and RPMl1640, were obtained from WELGENE Inc. (Korea). Human recombinant TNF $\alpha$ was purchased from R\&D systems (USA); and the protease inhibitor cocktail was purchased from Roche (Germany). Anti-NME1, anti-GFP, and anti-IкB were purchased from Santa Cruz Biotechnology (USA). All other chemical reagents and antibodies, such as anti-FLAG antibodies, were purchased from Sigma (USA).

\section{Plasmid construction}

IKK $\beta$ construct was amplified by PCR from the original cDNA clones and inserted into HindlII/Xbal sites of pCMV2 expression vector. Epitope tagged NME1L constructs were amplified by PCR from the original CDNA clones and inserted into Nhel/EcoRl sites of pcDNA3.1-GFP (GFP-inserted form of pcDNA3.1) expression vector, and inserted into EcoRI/Sall sites of pCMV2 expression vector, and inserted into EcoRl/Xhol sites of pcDNA3.1-HA expression vector. All constructs were confirmed by DNA sequencing. The shRNAs for human NME1, constructed in the pLKO.1 vector, were obtained from Thermo Fisher Scientific (USA); their inhibitory efficiency was examined by Western blot using anti-NME1 antibody (USA) in HEK293 cells. The shRNA-resistant forms of NME1L and N84-NME1L were constructed by site-directed mutagenesis using PCR and inserted into pcDNA3.1-HA vector.

\section{Immunoprecipitation and Western blotting}

HEK293 cells were maintained in DMEM in the presence of $10 \%$ fetal bovine serum (FBS) and penicillin/streptomycin. A day before transfection, cells were plated in $60 \mathrm{~mm}$ dishes at 1 $\times 10^{6} \mathrm{cells} / \mathrm{dish}$. The relevant plasmids were transfected with Lipofectamine 2000 transfection reagent (Invitrogen), in accordance with the manufacturer's instructions. After $36 \mathrm{~h}$, cells were washed with ice-cold PBS and solubilized with $1 \mathrm{ml}$ lysis buffer, containing $50 \mathrm{mM}$ Tris- $\mathrm{HCl}(\mathrm{pH} 7.5), 150 \mathrm{mM} \mathrm{NaCl}, 1 \%$ Triton X-100, and protease inhibitor cocktail, for $30 \mathrm{~min}$ on ice. The lysates were centrifuged at $15,000 \mathrm{rpm}$ for $10 \mathrm{~min}$ at $4^{\circ} \mathrm{C}$, then supernatants were incubated with anti-FLAG antibodyconjugated beads (Sigma) at $4^{\circ} \mathrm{C}$ for $2 \mathrm{~h}$. The beads were washed four times with lysis buffer. Bound proteins were eluted by boiling in sodium dodecyl sulfate (SDS) sample buffer and separated by SDS-polyacrylamide gel electrophoreses (SDSPAGE). To examine the expression of specific proteins, $20 \mu \mathrm{g}$ clarified lysate was loaded into each well of the gel. Proteins were transferred onto a nitrocellulose membrane and probed with the relevant antibodies, and then detected using the ECL assay kit (GE Healthcare Life Science, USA).

Reporter gene assay

For luciferase assays, HEK293 cells $\left(8 \times 10^{4}\right.$ cells/well) were 
A

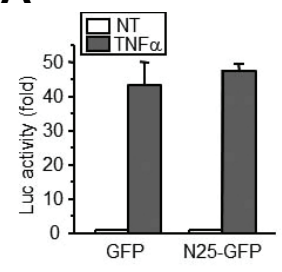

B

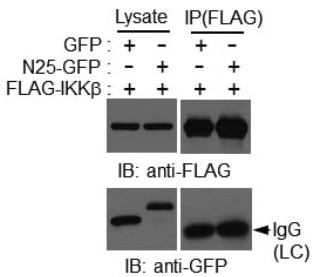

Fig. 1. N-terminal 25 amino acids of NME1L has no effect on NF- $\kappa B$ signaling. (A) HEK293 cells transfected with NF- $\mathrm{KB}$ luciferase reporter gene and plasmids of GFP-tagged $\mathrm{N}$-terminal 25 amino acids were treated with TNF $\alpha(10 \mathrm{ng} / \mathrm{ml})$ for $6 \mathrm{~h}$, and reporter gene assays were performed. N25, N-terminal 25 amino acids. (B) HEK293 cells expressing FLAG-IKK $\beta$ and N25-GFP were applied for immunoprecipitation with anti-FLAG antibodies. The precipitates were subjected to SDS-PAGE and subsequent Western blotting with appropriate antibodies. LC, immunoglobulin light chain.

cultured in 24-well plates 1 day before transfection and transfected with a liposome complex containing pGL3/NF-кBluciferase reporter gene $(50 \mathrm{ng}), \mathrm{pCMV} / \beta$-gal $(20 \mathrm{ng})$, and other relevant plasmids (400 $\mathrm{ng}$ ). After $24 \mathrm{~h}$, media were changed to serum-free DMEM. After $18 \mathrm{~h}$, cells were treated with TNF $\alpha$ (10 $\mathrm{ng} / \mathrm{ml}$, R\&D Systems) for $6 \mathrm{~h}$, washed with PBS, and harvested with lysis buffer. The luciferase activity of cell extracts was determined by using the standard luciferase assay system from BioTek Instruments, Inc. (USA). To determine transfection efficiency, luciferase activity was normalized to $\beta$-galactosidase ( $\beta$ gal) activity. Measurements were performed in triplicates and repeated at least three times.

\section{Migration assay}

HT1080 cells were incubated with the media containing 10 $\mathrm{ng} / \mathrm{ml}$ TNF $\alpha$ for $24 \mathrm{~h}$. A single cell suspension of HT1080 cells was obtained via trypsin-EDTA treatments for $2 \mathrm{~min}$ at $37^{\circ} \mathrm{C}$. For the migration assay, transwell inserts with $8 \mu \mathrm{m}$ pores (Corning Inc., USA) were purchased from Invitrogen (USA). Cells $\left(2 \times 10^{4}\right)$ in RPMI were added to the transwell inserts. The bottom of the wells was filled with RPMI containing $10 \%$ FBS. Plates were maintained in a humidified incubator with $5 \% \mathrm{CO}_{2}$ at $37^{\circ} \mathrm{C}$ for $24 \mathrm{~h}$. Transwell inserts were washed in PBS, and cells in the inner well that had not migrated were removed with a cotton swab. Membranes were fixed in $4 \%$ formalin and stained with hematoxylin, and then cells that had migrated were counted in 5 high power fields under the microscope.

\section{Quantitative RT-PCR}

To quantitate mRNA levels, total RNA was isolated using TRIzol (Invitrogen) according to the manufacturer's instructions. CDNA was prepared using reverse transcriptase from Promega and real-time quantitative PCR was performed using $\mathrm{IQ}^{\mathrm{TM}}$ SYBR Green Supermixture and an iCycler PCR thermocycler (BioRad) with gene-specific primer sets designed by Beacon Designer 2.1 (Biosoft International): UPA (5'-ttgctcaccacaacgacatt- $3^{\prime}$ and $5^{\prime}$-ggcaggcagatggtctgtat- $\left.3^{\prime}\right), P A I$ ( $5^{\prime}$-actggaaaggcaacatgacc- $3^{\prime}$ and $5^{\prime}$-ctctaggggcttcctgaggt- $\left.3^{\prime}\right)$, MMP2 (5'-cggaaaagattgatgcggta- $3^{\prime}$ and $5^{\prime}$-tgctggctgagtagatccag- $\left.3^{\prime}\right), I L-8$ ( $5^{\prime}-$ gagcactccataaggcacaaa- $3^{\prime}$ and $5^{\prime}$-ggttccttccggtggt- $\left.3^{\prime}\right)$, and GAPDH (5'-ctctgctcctcctgttcgac- $3^{\prime}$ and $5^{\prime}$-aatccgttgactccgacctt$\left.3^{\prime}\right)$. The mRNA level of each gene was normalized to that of glyceraldehyde 3-phosphate dehydrogenase (GAPDH). Data

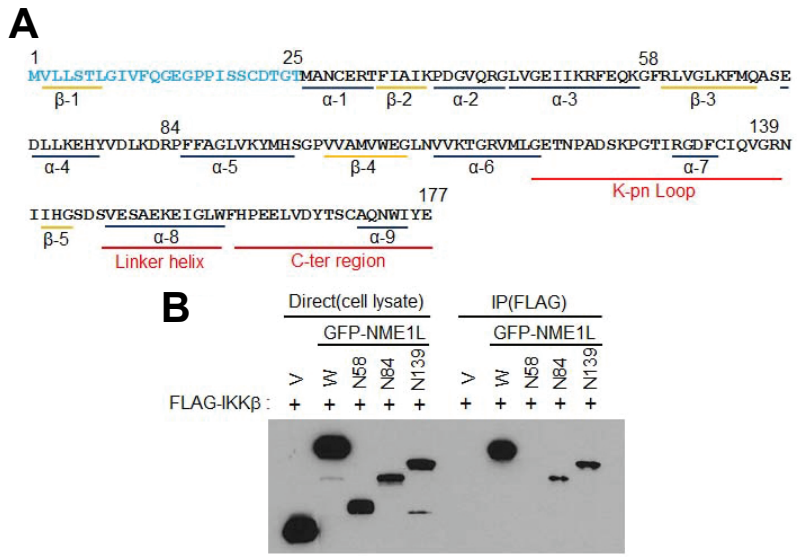

Fig. 2. Analysis of the domains of NME1L responsible for IKK $\beta$ binding. (A) Secondary structure and functionally important domain in NME1L. An $\alpha, \alpha$-helix; $\beta, \beta$-strand. (B) Cells ectopically expressing FLAG-IKK $\beta$ with each of GFP-tagged NME1L fragments were applied for immunoprecipitation with anti-FLAG antibodies. Co-precipitates were detected with anti-GFP antibodies.

from three independent experiments, carried out in triplicate, were combined.

\section{Statistical analysis}

Data from more than three independent experiments, carried out in triplicate, were combined, and the results were presented as means \pm S.E. Statistical differences were assessed using PRISM4 software (GraphPad). Group means were compared using one-way analysis of variance with Student's $t$ test.

\section{RESULTS}

$\mathrm{N}$-terminal sequence of NME1L is not enough to act as a functional domain

In a previous study NME1L but not NME1 was found to bind IKK $\beta$ directly, thereby indicating that $\mathrm{N}$-terminal 25 amino acids are necessary for the interaction. Thus, the question arose as to whether the amino acid sequences may be the only motif to participate in the binding. To examine the binding property we constructed the peptide as a GFP-tagging form because it is too short to be expressed in cells. After being transfected with the constructs and the reporter gene plasmids, the cells were treated with TNF $\alpha$. The agonist induced NF-kB-derived luciferase expression with almost the same efficiency in both groups (Fig. 1A). Immunoprecipitation, using FLAG agarose, showed that GFPtagged N-terminal peptide was not co-precipitated with FLAGIKK $\beta$. These results suggest that the $\mathrm{N}$-terminal sequences in NME1L are essential but not enough for IKK $\beta$ binding.

Identification of the domain responsible for IKK $\beta$ interaction and $N F-k B$ signaling regulation

According to structure analysis in previous reports, NME1 consists of a combination of $8 \alpha$-helixes and $4 \beta$-sheets. Its general structure has a globular $\alpha / \beta$ domain with a ferredoxin-like fold and an extended C-terminal domain (Min et al., 2002; Kim et al., 2013). Second structure prediction analysis (at http://www. compbio.dundee.ac.uk/www-jpred) showed one more $\beta$-sheet $\left(\mathrm{V}_{2}-\mathrm{L}_{7}\right)$ and $\alpha$-helix $\left(\mathrm{M}_{26}-\mathrm{T}_{32}\right)$ in $\mathrm{N}$-terminal region of NME1L (Fig 2A). NME1 exists as a hexamer consisting of three dimers in 
A

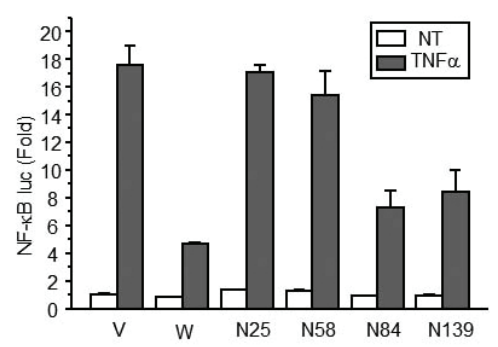

B

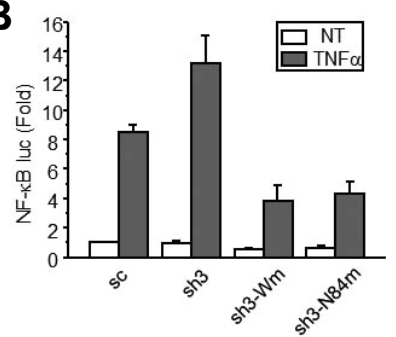

C

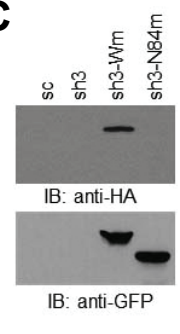

Fig. 3. Regulation of NF- $\mathrm{KB}$ reporter gene activity by NME1L fragments. (A) Cells transfected with NF-kB-luciferase reporter gene and each of HA-tagged NME1L fragment plasmids were treated with TNF $\alpha(10 \mathrm{ng} / \mathrm{ml})$ for $6 \mathrm{~h}$, and then applied for luciferase assay. (B) Cells stably expressing shRNA against NME1 gene were transfected with NF-KB-luciferase gene and each of NME1L constructs resistant to shRNA. Cells were used for reporter gene assay. Sc, scrambled shRNA; sh3, shRNA specific for human NME1 gene; Wm, NME1L resistant to shRNA; N84m, N-terminal 84 amino acids resistant to shRNA. (C) Expression test of NME1L constructs resistant to shRNA. Cells transfected with NME1L constructs (HAtagged form or GFP-tagged form) resistant to shRNA were lysed and applied for western blotting with appropriate antibodies. (A, B) Data from three independent experiments, done in triplicate, were combine and are presented as the mean \pm S.E. (error bars). * , compared with TNF $\alpha$-treated in vector or sc, $p<0.01$.

physiological condition. This hexamer likely acts as a functional unit to harbor enzymatic activity. In this simple structure any known functional domain or motif has not been identified yet. To further determine the region involved in IKK $\beta$ interaction we constructed fragments of NME1L, including N-terminus. Immunoprecipitation and subsequent western blot revealed that $\mathrm{N} 84\left(\mathrm{M}_{1}-\mathrm{P}_{84}\right)$ is the minimum fragment to bind IKK $\beta$, suggesting that N84 could make the architecture attending to IKK $\beta$ binding (Fig. 2B).

Next, we examined whether the fragment is enough to regulate NF-кB signaling. After transfection with genes encoding each fragment and reporter gene plasmids, cells were treated with TNF $\alpha$ and applied for luciferase assay. The whole protein of NME1L efficiently inhibited NF-KB activation, and N84 and N139 fragments decreased the activity by more than $50 \%$, indicating N84 fragment seems to inhibit IKK $\beta$ activity by direct interaction. However, N84 and N139 may be enough to form the fully active form to regulate IKK $\beta$ (Fig. 3A). In this experimental condition, there are still endogenous NME1 that may affect function of the fragments. To determine whether the fragment itself regulates NF- $\mathrm{KB}$ signaling, we established the cells lacking NME1 proteins by infecting lentivirus containing shRNAs for NME1 gene, as previously described in the literature (You et al., 2014). In the absence of NME1 proteins TNF $\alpha$
A

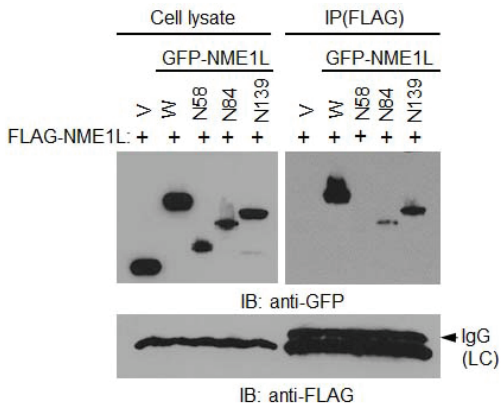

B

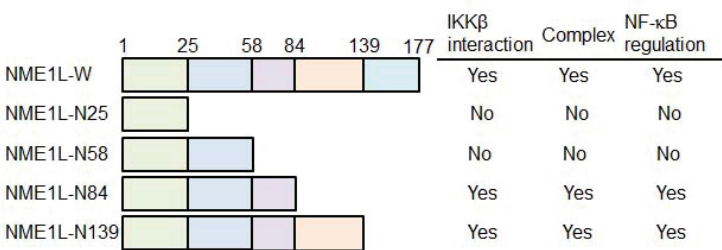

Fig. 4. Analysis of complex formation of NME1L fragments. (A) Cells expressing FLAG-tagged NME1L and each of GFP-tagged NME1L fragments were applied for immunoprecipitation with antiFLAG antibodies. The precipitates were detected with appropriate antibodies. LC, immunoglobulin light chain. (B) Schematics of NME1L fragments and functional properties of them.

could enhance the reporter gene expression in comparison with cells harboring scrambled shRNAs (sc). The NME1-null cells were transfected with the reporter gene and the plasmids containing mutant genes of whole NME1L or N84 fragment. The mutant genes are resistant to shRNA-mediated degradation and encode wild type proteins because the shRNA target sequences were substituted with other nucleotides encoding the same amino acids with a wild type. TNF $\alpha$-stimulated luciferase expression was significantly decreased by both forms, implying that N84 fragment is likely enough to regulate IKK $\beta$ activity (Fig. $3 \mathrm{~B})$. The reporter gene assays were performed with cells expressing either HA-tagging or GFP-tagging proteins, and the experimental outputs were similar regardless of the epitopes. However, HA-tagging forms of N84 fragment were hardly detected in western blotting, possibly owing to the size of the fragments (Fig. 3C).

\section{IKKß-binding region are also involved in NME1L complex formation}

NME1 proteins may form hexameric complex to obtain biological function (Hartsough and Steeg, 2000). To examine the binding capacity of the fragments to attend complex formation, we performed immunoprecipitation with cells expressing whole NME1L and each of the fragments. The N84 and N139 were co-precipitated with whole NME1L, indicating that the N84 may be necessary to form a protein complex (see Fig. 4A). To examine if the N84 fragments are able to bind each other to form a homodimer, the fragment was expressed as an epitope tagging form with HA or FLAG in cells. However, since the fragment was not detected with appropriate antibodies, homodimerization of the fragments was not confirmed. This implies that their expression levels may be too low to be detected in western blotting or are unstable and disappear during sample preparation, although the fragments tagged with small epitope 
A

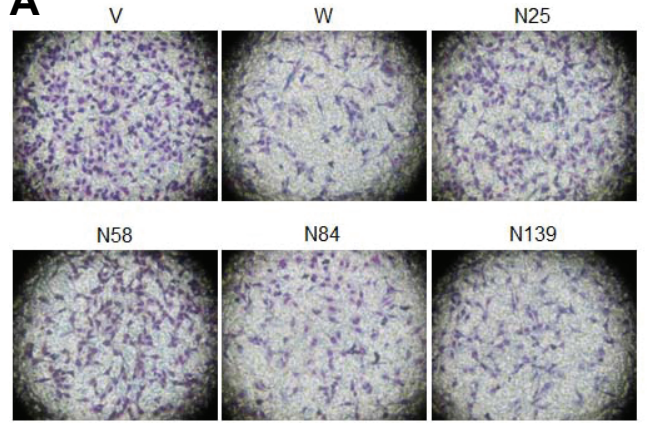

B

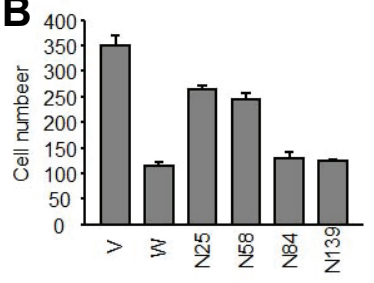

Fig. 5. Effect of NME1L fragments on cell migration. (A) HT1080 cells stably expressing NME1L fragments were incubated with TNF $\alpha$ for $24 \mathrm{~h}$. Trypsinized cells were loaded on transwell insert and $10 \%$ FBS-containing media were added to bottom well. $24 \mathrm{~h}$ later, migrated cells were fixed, stained with hematoxylin. (B) Migrated cells were photographed under microscopy and counted at 5 different fields. Data from three independent experiments, done in triplicate, were combined and are presented as the mean \pm S.E. (error bars). ${ }^{*}$, compared with vector-containing cells, $p$ $<0.01$. still function effectively in the regulation of signaling pathway. The functional properties of NME1L fragments were summarized in Fig. 4B. Interestingly, the fragments able to form a complex also interact with IKK $\beta$ and regulate NF- $\kappa B$ activation, suggesting that the $\mathrm{N}$-terminal region is likely to interact with and regulate $\mathrm{IKK} \beta$ by making functional structures with other regions or through homo-oligomerization.

\section{Expression of NME1L fragment regulates TNFo-stimulated migration activity}

Previously, NME1L has been reported to downregulate TNF $\alpha$ dependent chemotactic activity as well as TNF $\alpha$-stimulated gene expression (You et al., 2014). Reporter gene assay revealed that expression of the $\mathrm{N}$-terminal 84 amino acids efficiently inhibited TNF $\alpha$-stimulated NF- $\mathrm{NB}$ activation with almost equivalent potency to the whole protein (Fig. $3 \mathrm{~A}$ ). To examine the effect of the fragment on cell migration, HT1080 cells, expressing the NME1L fragments, were applied for transwell migration assay. Migration activity was remarkably suppressed in cells expressing whole NME1L, N84, and N139 fragments with similar potency, which may reflect their interaction with IKK $\beta$, and inhibition of NF- $\mathrm{kB}$ activation (Figs. $5 \mathrm{~A}$ and $5 \mathrm{~B}$ ).

In previous study, NME1L inhibited TNF $\alpha$-stimulated expression of the genes responsible for cell migration and metastasis through NF-KB (You et al., 2014). To determine the effect on endogenous pro-metastatic gene expression, real-time quantitative RT-PCR was performed with HT1080 cells expressing the NME1L fragments. mRNA levels of MMP2, PAI, UPA, and IL-8 were increased by TNF $\alpha$ treatment, but they were prominently downregulated in the cells expressing wild type and N84 fragment of NME1L with almost same potency (Fig. 6). This data suggests that NME1L may inhibit TNF $\alpha$-stimulated cellular responses by direct interaction with $I \mathrm{KK} \beta$ through the structure consisting of $\mathrm{N}$-terminal 84 amino acids.

\section{DISCUSSION}

NME proteins have been extensively studied for their biological roles, especially because of multifunctional enzymatic activities in many cellular responses. Although NME proteins are relatively small and the functional domains required for the enzymatic activities are not defined precisely, mutation studies and amino acid sequence alignment revealed which residues are involved in the enzymatic activity. In NME1, Glu5 is the key residue for 3'-5' exonuclease activity. Tyr52 and His 118 are essential for both NDPK and histidine kinase activities. Furthermore, all three enzyme activities were abrogated by mutation of Lys12. Zhou et al. (2007) reported that mutation of Pro96 and Ser120
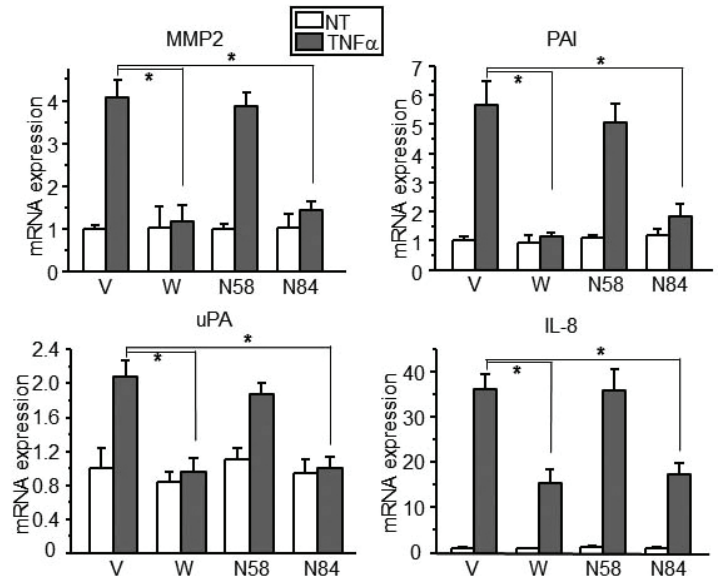

Fig. 6. Effect of NME1L fragments on TNF $\alpha$-stimulated gene expression. HT1080 cells expressing NME1L or the fragments were treated with (gray bars) and without (white bars) $10 \mathrm{ng} / \mathrm{ml} \mathrm{TNF} \alpha$ for $24 \mathrm{~h}$. cDNAs were synthesized by reverse transcription, and realtime PCR was carried out using gene-specific primers. The relative amount of RNA obtained from each sample was calculated from a standard curve and normalized with GAPDH RNA. Data from three independent experiments, done in triplicate, were combined and are presented as the mean \pm S.E. (error bars). ${ }^{*} P<0.01$

also impaired NDPK activity and motility suppression of NME1, implying NDPK activity may be necessary for its anti-metastatic activity. However, structural analysis with the wild type and Ser120 mutant indicated that the mutation might affect other protein properties rather than NDPK activity, implying dispensability of the enzymatic activity on the tumor metastasis suppression (Giraud et al., 2006).

Usually, NME proteins exist as an oligomer ranging from a dimer to hexamer, and the complex structure is diverse depending on the organism. In humans, the hexameric formation of NME1 has been considered to be essential for the antimetastatic activity (Kim et al., 2003). This oligomeric conformation may provide the interaction sites with at least 20 different binding partners, and thus NME1 performs diverse cellular function (Marino et al., 2011). Structural analysis showed that dimer mediated by the $\mathrm{N}$-terminal region (residues 24-40) is likely a minimal subunit and a functional hexameric state may be stabilized by interaction between the K-pn loop regions (residues 117-139) and the C-terminal domain of a neighboring 
subunit (Kim et al., 2013). In oxidative condition, modification of some cysteine residues facilitates conformational change in the $\mathrm{K}$-pn loop and dissociation of the hexamer into dimers (Song et al., 2000). According to some reports, the tumor suppressor activity of NME1 may be lost in the dimeric conformation owing to the deformation of the regions involved in the interaction with binding partner proteins (Lee et al., 2009). Previous studies showed that NME1L containing extra 25 residues in the $\mathrm{N}$ terminal more efficiently suppressed tumor cell metastasis compared with NME1, suggesting that IKK $\beta$ interaction with those residues and inhibition of the kinase activity is another important mechanism underlying its anti-metastatic effect (You et al., 2014).

Since the inhibitory effect of NME1L was potent, the question arose if the $\mathrm{N}$-terminal region itself may be enough to conduct molecular activity on tumor progression. However, the 25 residues neither interacted with IKK $\beta$ nor inhibited TNF $\alpha$-stimulated $\mathrm{NF}-\mathrm{\kappa B}$ activation, indicating that the region is not able to constitute a functional motif by itself. Interestingly, the fragment containing the $\mathrm{N}$-terminus and dimeric interface (described as N84) was readily precipitated with $\mathrm{IKK} \beta$ in conimmunoprecipitation assay. The fragment was also precipitated with whole NME1L. Furthermore, TNF $\alpha$-stimulated NF-kB activation was remarkably downregulated in cells expressing the fragment, which was almost equivalent to the effect of whole NME1L. Whereas, the fragment, containing an incomplete dimeric interface (N58) lacking $\beta$-sheet, was not able to form a complex with other NME1L and to interact with IKK $\beta$, and consequently had no effect on NF-KB signaling. These results demonstrate that $\mathrm{NME} 1 \mathrm{~L}$ regulation of IKK $\beta$-mediated $\mathrm{NF}-\mathrm{KB}$ signaling may be efficiently conducted by dimeric conformation rather than hexamer. N84 and N139 fragments seem not to exist as more than dimers since multimeric conformation are mediated by the K-pn loop and C-terminal region. However, homodimerization of the fragments was not confirmed in immunoprecipitation because expression of the fragments containing HA or FLAG was hardly detected. Nevertheless, the fragments containing the small epitopes are likely expressed enough to biologically function in

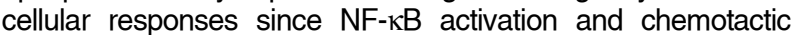
activities are regulated in cells expressing them.

In regard to anti-metastatic activity of NME1, most reports have focused on its hexameric conformation as a functional unit. This study reveals that NME1L may perform potent biological roles on the cellular behaviors through the extra N-terminal region as well as hexameric conformation. Because the $\mathrm{N}$ terminal region itself has no effect on NF- $\mathrm{KB}$ signaling, the dimerization of NME1L is likely a pivotal process to confer the IKK $\beta$ binding ability and subsequent regulation of NF- $\kappa B$ signaling on the region. Understanding the roles of NME1L in cancer progression through binding properties with IKK $\beta$ may provide direction to NME1L and IKK $\beta$-related anti-cancer drug design.

\section{ACKNOWLEDGMENTS}

This work was supported by the Korea Research Foundation Grant to J.-I. H. funded by the Korean Government (Ministry of Science, ICT and Future Planning: MSIP) (no. NRF-2013R1A1 A2005949).

\section{REFERENCES}

Amendola, R., Martinez, R., Negroni, A., Venturelli, D., Tanno, B., Calabretta, B., and Raschella, G. (1997). DR-nm23 gene expression in neuroblastoma cells: relationship to integrin expression, adhesion characteristics, and differentiation. J. Natl. Cancer Inst. 89, 1300-1310.
Boissan, M., De Wever, O., Lizarraga, F., Wendum, D., Poincloux, R., Chignard, N., Desbois-Mouthon, C., Dufour, S., NawrockiRaby, B., Birembaut, P., et al. (2010). Implication of metastasis suppressor NM23-H1 in maintaining adherens junctions and limiting the invasive potential of human cancer cells. Cancer Res. 70, 7710-7722.

Cheng, S., Alfonso-Jaume, M.A., Mertens, P.R., and Lovett, D.H. (2002). Tumour metastasis suppressor, nm23-beta, inhibits gelatinase $A$ transcription by interference with transactivator $Y$ box protein-1 (YB-1). Biochem. J. 366, 807-816.

Dearolf, C.R., Tripoulas, N., Biggs, J., and Shearn, A. (1988). Molecular consequences of awdb3, a cell-autonomous lethal mutation of Drosophila induced by hybrid dysgenesis. Dev. Biol. 129, 169-178.

Giraud, M.F., Georgescauld, F., Lascu, I., and Dautant, A. (2006). Crystal structures of S120G mutant and wild type of human nucleoside diphosphate kinase $A$ in complex with ADP. J. Bioenerg. Biomembr. 38, 261-264.

Hartsough, M.T., and Steeg, P.S. (2000). Nm23/nucleoside diphosphate kinase in human cancers. J. Bioenerg. Biomembr. 32, 301-308.

Horak, C.E., Lee, J.H., Elkahloun, A.G., Boissan, M., Dumont, S. Maga, T.K., Arnaud-Dabernat, S., Palmieri, D., Stetler-Stevenson, W.G., Lacombe, M.L., et al. (2007). Nm23-H1 suppresses tumor cell motility by down-regulating the lysophosphatidic acid receptor EDG2. Cancer Res. 67, 7238-7246.

Keim, D.R., Hailat, N., Kuick, R., Reynolds, C.P., Brodeur, G.M., Seeger, R.C., and Hanash, S.M. (1993). PCNA levels in neuroblastoma are increased in tumors with an amplified N-myc gene and in metastatic stage tumors. Clin. Exp. Metastasis 11, 83-90.

Kim, Y.I., Park, S., Jeoung, D.I., and Lee, H. (2003). Point mutations affecting the oligomeric structure of $\mathrm{Nm} 23-\mathrm{H} 1$ abrogates its inhibitory activity on colonization and invasion of prostate cancer cells. Biochem. Biophys. Res. Commun. 307, 281-289

Kim, H.D., Youn, B., Kim, T.S., Kim, S.H., Shin, H.S., and Kim, J. (2009). Regulators affecting the metastasis suppressor activity of Nm23-H1. Mol. Cell Biochem. 329, 167-173.

Kim, M.S., Jeong, J., Shin, D.H., and Lee, K.J. (2013). Structure of Nm23-H1 under oxidative conditions. Acta Crystallogr. D Biol. Crystallogr. 69, 669-680.

Kwon, C.H., Moon, H.J., Park, H.J., Choi, J.H., and Park do, Y. (2013). S100A8 and S100A9 promotes invasion and migration through p38 mitogen-activated protein kinase-dependent NFkappaB activation in gastric cancer cells. Mol. Cells 35, 226-234.

Lacombe, M.L., Milon, L., Munier, A., Mehus, J.G., and Lambeth, D.O. (2000). The human Nm23/nucleoside diphosphate kinases. J. Bioenerg. Biomembr. 32, 247-258.

Lascu, I., and Gonin, P. (2000). The catalytic mechanism of nucleoside diphosphate kinases. J. Bioenerg. Biomembr. 32, 237-246.

Lee, E., Jeong, J., Kim, S.E., Song, E.J., Kang, S.W., and Lee, K.J. (2009). Multiple functions of $\mathrm{Nm} 23-\mathrm{H} 1$ are regulated by oxidoreduction system. PLoS One 4, e7949.

Ma, D., Xing, Z., Liu, B., Pedigo, N.G., Zimmer, S.G., Bai, Z., Postel, E.H., and Kaetzel, D.M. (2002). NM23-H1 and NM23-H2 repress transcriptional activities of nuclease-hypersensitive elements in the platelet-derived growth factor-A promoter. J. Biol. Chem. 277, 1560-1567.

Marino, N., Marshall, J.C., and Steeg, P.S. (2011). Protein-protein interactions: a mechanism regulating the anti-metastatic properties of Nm23-H1. Naunyn. Schmiedebergs Arch. Pharmacol. 384, 351362.

Martinez, J.A., Prevot, S., Nordlinger, B., Nguyen, T.M., Lacarriere, Y., Munier, A., Lascu, I., Vaillant, J.C., Capeau, J., and Lacombe, M.L. (1995). Overexpression of $n m 23-\mathrm{H} 1$ and $\mathrm{nm} 23-\mathrm{H} 2$ genes in colorectal carcinomas and loss of $\mathrm{nm} 23-\mathrm{H} 1$ expression in advanced tumour stages. Gut 37, 712-720.

Min, K., Song, H.K., Chang, C., Kim, S.Y., Lee, K.J., and Suh, S.W. (2002). Crystal structure of human nucleoside diphosphate kinase A, a metastasis suppressor. Proteins 46, 340-342.

Munier, A., Serres, C., Kann, M.L., Boissan, M., Lesaffre, C., Capeau, J., Fouquet, J.P., and Lacombe, M.L. (2003). Nm23/NDP kinases in human male germ cells: role in spermiogenesis and sperm motility? Exp. Cell Res. 289, 295-306. 
Murakami, M., Meneses, P.I., Knight, J.S., Lan, K., Kaul, R., Verma, S.C., and Robertson, E.S. (2008). Nm23-H1 modulates the activity of the guanine exchange factor Dbl-1. Int. J. Cancer 123, 500-510.

Okabe-Kado, J., Kasukabe, T., Hozumi, M., Honma, Y., Kimura, N., Baba, H., Urano, T., and Shiku, H. (1995). A new function of Nm23/NDP kinase as a differentiation inhibitory factor, which does not require it's kinase activity. FEBS Lett. 363, 311-315.

Otsuki, Y., Tanaka, M., Yoshii, S., Kawazoe, N., Nakaya, K., and Sugimura, H. (2001). Tumor metastasis suppressor $\mathrm{nm} 23 \mathrm{H} 1$ regulates Rac1 GTPase by interaction with Tiam1. Proc. Natl. Acad. Sci. USA 98, 4385-4390.

Ouatas, T., Salerno, M., Palmieri, D., and Steeg, P.S. (2003). Basic and translational advances in cancer metastasis: Nm23. J. Bioenerg. Biomembr. 35, 73-79.

Postel, E.H. (1999). Cleavage of DNA by human NM23-H2/ nucleoside diphosphate kinase involves formation of a covalent protein-DNA complex. J. Biol. Chem. 274, 22821-22829.

Salerno, M., Palmieri, D., Bouadis, A., Halverson, D., and Steeg, P.S. (2005). Nm23-H1 metastasis suppressor expression level influences the binding properties, stability, and function of the kinase suppressor of Ras1 (KSR1). Erk scaffold in breast carcinoma cells. Mol. Cell Biol. 25, 1379-1388.

Schlattner, U., Tokarska-Schlattner, M., Ramirez, S., Tyurina, Y.Y., Amoscato, A.A., Mohammadyani, D., Huang, Z., Jiang, J., Yanamala, N., Seffouh, A., et al. (2013). Dual function of mitochondrial $\mathrm{Nm} 23-\mathrm{H} 4$ protein in phosphotransfer and intermembrane lipid transfer: a cardiolipin-dependent switch. J. Biol. Chem. 288, 111-121.

Seong, H.A., Jung, H., and Ha, H. (2007). NM23-H1 tumor suppressor physically interacts with serine-threonine kinase receptor-associated protein, a transforming growth factor-beta (TGF-beta). receptor-interacting protein, and negatively regulates TGF-beta signaling. J. Biol. Chem. 282, 12075-12096.

Song, E.J., Kim, Y.S., Chung, J.Y., Kim, E., Chae, S.K., and Lee, K.J. (2000). Oxidative modification of nucleoside diphosphate kinase and its identification by matrix-assisted laser desorption/ ionization time-of-flight mass spectrometry. Biochemistry 39, 10090-10097.

Steeg, P.S., Bevilacqua, G., Pozzatti, R., Liotta, L.A., and Sobel, M.E. (1988). Altered expression of NM23, a gene associated with low tumor metastatic potential, during adenovirus 2 Ela inhibition of experimental metastasis. Cancer Res. 48, 6550-6554.

Steeg, P.S., Horak, C.E., and Miller, K.D. (2008). Clinical-translational approaches to the Nm23-H1 metastasis suppressor. Clin. Cancer Res. 14, 5006-5012.
Tokunaga, Y., Urano, T., Furukawa, K., Kondo, H., Kanematsu, T., and Shiku, H. (1993). Reduced expression of nm23-H1, but not of $n$ m23- $\mathrm{H} 2$, is concordant with the frequency of lymph-node metastasis of human breast cancer. Int. J. Cancer 55, 66-71.

Tseng, Y.H., Vicent, D., Zhu, J., Niu, Y., Adeyinka, A., Moyers, J.S., Watson, P.H., and Kahn, C.R. (2001). Regulation of growth and tumorigenicity of breast cancer cells by the low molecular weight GTPase Rad and nm23. Cancer Res. 61, 2071-2079.

Venturelli, D., Martinez, R., Melotti, P., Casella, I., Peschle, C., Cucco, C., Spampinato, G., Darzynkiewicz, Z., and Calabretta, B. (1995). Overexpression of DR-nm23, a protein encoded by a member of the nm23 gene family, inhibits granulocyte differentiation and induces apoptosis in 32Dc13 myeloid cells. Proc. Natl. Acad. Sci. USA 92, 7435-7439.

Wallet, V., Mutzel, R., Troll, H., Barzu, O., Wurster, B., Veron, M., and Lacombe, M.L. (1990). Dictyostelium nucleoside diphosphate kinase highly homologous to $\mathrm{Nm} 23$ and Awd proteins involved in mammalian tumor metastasis and Drosophila development. J. Natl. Cancer Inst. 82, 1199-1202.

Wang, C.H., Ma, N., Lin, Y.T., Wu, C.C., Hsiao, M., Lu, F.L., Yu, C.C., Chen, S.Y., and Lu, J. (2012). A shRNA functional screen reveals Nme6 and Nme7 are crucial for embryonic stem cell renewal. Stem Cells 30, 2199-2211.

Yang, M., Jarrett, S.G., Craven, R., and Kaetzel, D.M. (2009). YNK1, the yeast homolog of human metastasis suppressor NM23, is required for repair of UV radiation- and etoposideinduced DNA damage. Mutat. Res. 660, 74-78.

You, D.J., Park, C.R., Lee, H.B., Moon, M.J., Kang, J.H., Lee, C., Oh, S.H., Ahn, C., Seong, J.Y., and Hwang, J.I. (2014). A splicing variant of NME1 negatively regulates NF-kappaB signaling and inhibits cancer metastasis by interacting with IKKbeta. J. Biol. Chem. 289, 17709-17720.

Zhang, Q., McCorkle, J.R., Novak, M., Yang, M., and Kaetzel, D.M., (2011). Metastasis suppressor function of NM23-H1 requires its $3^{\prime}-5^{\prime}$ exonuclease activity. Int. J. Cancer 128, 40-50.

Zhou, Q., Yang, X., Zhu, D., Ma, L., Zhu, W., Sun, Z., and Yang, Q. (2007). Double mutant P96S/S120G of Nm23-H1 abrogates its NDPK activity and motility-suppressive ability. Biochem. Biophys. Res. Commun. 356, 348-353.

Zhu, J., Tseng, Y.H., Kantor, J.D., Rhodes, C.J., Zetter, B.R. Moyers, J.S., and Kahn, C.R. (1999). Interaction of the Rasrelated protein associated with diabetes rad and the putative tumor metastasis suppressor NM23 provides a novel mechanism of GTPase regulation. Proc. Natl. Acad. Sci. USA 96, 1491114918. 